\title{
Effect of oral calcium administration on the cure and reproductive performance of Holstein cows diagnosed with puerperal metritis
}

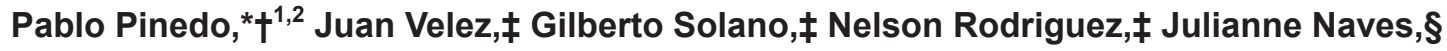 \\ Gustavo M. Schuenemann,\# and Carlos Riscoll \\ *Texas A\&M AgriLife Research, Texas A\&M University System, Amarillo 79106 \\ †Department of Veterinary Pathobiology, College of Veterinary Medicine and Biomedical Sciences, Texas A\&M University System, \\ College Station 77843 \\ $\ddagger$ Aurora Organic Farms, Platteville, CO 80651 \\ $\S$ College of Veterinary Medicine, University of São Paulo, Pirassununga, SP, Brazil \\ \#Department of Veterinary Preventive Medicine, College of Veterinary Medicine, The Ohio State University, Columbus 43210 \\ \|College of Veterinary Medicine, University of Florida, Gainesville 32608
}

\begin{abstract}
Our objective was to evaluate the effect of oral calcium administration on clinical cure, survival, subsequent presentation of peripartal health disorders, and reproductive performance of Holstein cows diagnosed with puerperal metritis (PM) under certified organic management. A second objective was to evaluate the metabolic status at calving and at the time of PM diagnosis (d 0) in affected and matched healthy cows. Cows diagnosed with PM $(\mathrm{n}=200)$ were assigned randomly to receive 1 of 2 treatments: (1) control received 3.75 $\mathrm{mL}$ of Optimum UterFlush [Van Beek Natural Science, Orange City, IA, containing yucca extract, cinnamaldehyde, thymol, and a proprietary blend of carvacrol (4-isopropyl-2-methylphenol, at $0.47 \mathrm{~g} / \mathrm{mL}$ )] diluted in $117 \mathrm{~mL}$ of distilled water by intrauterine infusion, administered every other day for a total of 3 treatments $(\mathrm{n}=100) ;(2)$ calcium-supplemented (CA) received the same intrauterine treatment plus 6 oral capsules providing calcium ('O' Cal-D Cap, Bio-Vet Inc., Barneveld, WI; 7.5-9.0 g of $\mathrm{Ca} /$ capsule) once per day, for 3 consecutive days after diagnosis of PM. All cows received hypertonic saline solution $(500 \mathrm{~mL}$ of $7.2 \%$ solution i.v. once), dextrose (500 $\mathrm{mL}$ of $50 \%$ solution i.v. once), and oral aspirin ( 5 boluses/d for $3 \mathrm{~d}$ ). Outcome variables included fever, presence of fetid vaginal discharge, and uterine score at d 6 and 14 after diagnosis, survival at 30 and $100 \mathrm{~d}$ in milk, reproductive performance, and incidence of other health disorders after PM. A group of 200 control healthy cows $(\mathrm{CH})$ was matched with

Received June 7, 2016.

Accepted January 1, 2017.

${ }^{1}$ Current address: Department of Animal Sciences, Colorado State University, Fort Collins, CO 80523-1171.

${ }^{2}$ Corresponding author: pablo.pinedo@colostate.edu
\end{abstract}

PM cows at $\mathrm{d} 0$, and calcium and fatty acid serum concentrations were determined at calving and at the day of diagnosis of PM (d 0). Calcium status was also assessed in PM cows at d 1, 2, 3, and 6 after diagnosis. Treatment effects were tested by logistic regression, repeated measures analysis, and ANOVA. Average calcium serum concentrations at d 0 were lower in PM cows $(1.57 \mathrm{mmol} / \mathrm{L})$ compared with $\mathrm{CH}$ cows $(2.10$ $\mathrm{mmol} / \mathrm{L})$. In PM cows, calcium concentrations at $\mathrm{d}$ $1,2,3$, and 6 after diagnosis were significantly higher in the CA group. Fatty acid serum concentrations at calving and at $\mathrm{d} 0$ were higher in PM cows compared with $\mathrm{CH}$ cows (0.48 vs. $0.37 \mathrm{mmol} / \mathrm{L}$ and 0.49 vs. 0.35 $\mathrm{mmol} / \mathrm{L}$, for calving and $\mathrm{d} 0$ ). No effect was observed for calcium administration on health and survival outcomes. However, the proportion of cows inseminated by $150 \mathrm{~d}$ in milk was greater for CA compared with control cows (66 vs. 55\%). In conclusion, supplementing oral calcium at the time of diagnosing PM had no effect on health. High fatty acid concentrations at calving were significant risk factors for occurrence of PM. Furthermore, cows affected with PM had lower calcium and higher fatty acid concentrations than $\mathrm{CH}$ cows at $\mathrm{d} 0$. Key words: puerperal metritis, calcium, fatty acid

\section{INTRODUCTION}

The peripartum period is a critical time for cow health and survival. Calving is accompanied by significant endocrine changes (Grummer et al., 2004), and highproducing dairy cows require drastic metabolic adjustments to support milk synthesis. The abrupt increase in nutrient requirements at a time when feed intake is depressed results in a shift from a positive to a negative energy balance, where fat mobilization increases fatty acid concentrations. Simultaneously, peripartal synthesis and secretion of colostrum result in major losses of 
Ca (Horst et al., 2005; Kimura et al., 2006; Martinez et al., 2012). As a response to low serum Ca concentrations, homeostatic mechanisms that include intestinal absorption and bone resorption are activated, but in many cases subclinical or clinical hypocalcemia conditions are unavoidable (Reinhardt et al., 2011). These events and concurrent immune suppression related to calving result in suboptimal health and performance in the affected cows (Goff, 2004; Burton et al., 2005; Hammon et al., 2006).

Uterine diseases, such as metritis and endometritis, are highly prevalent in high-producing dairy cows and are associated with decreased pregnancy per AI, extended interval to pregnancy, increased culling, and economic losses (Sheldon and Dobson, 2004; Gilbert et al., 2005; LeBlanc, 2008). In addition, animal welfare is compromised by metritis, as affected cows suffer from loss of appetite, often become dehydrated, and may also show signs of pain (Sheldon et al., 2006; Stojkov et al., 2015).

The incidence of metritis in dairy cows ranges from 10 to $36 \%$ (Santos et al., 2010; Chapinal et al., 2011) and the disorder is more frequently diagnosed during the first week postpartum (Sheldon et al., 2006). A more severe condition, puerperal metritis (PM), defined as an acute systemic illness due to infection of the uterus with bacteria, usually within $21 \mathrm{~d}$ after parturition (Sheldon et al., 2006), is a life-threatening condition affecting a significant number of cows.

According to a survey conducted in 2002 (NAHMS, 2002), the incidence of milk fever in US dairy herds averaged $5.2 \%$, and as reviewed by DeGaris and Lean (2008), in 10 European studies the incidence was $6.17 \%$, and for 10 Australasian studies it was 3.5\%. Nevertheless, the prevalence of subclinical hypocalcemia (SCH) remains at 25 and $47 \%$ in primiparous and multiparous cows, respectively (Reinhardt et al., 2011; Martinez et al., 2014). Hypocalcemic cows have reduced feed intake and rumination, increased plasma concentrations of cortisol (Horst and Jorgensen, 1982; Hansen et al., 2003), limited numbers of neutrophils with phagocytic activity (Ducusin et al., 2003; Martinez et al., 2012, 2014), and reduced concentrations of cytosolic $\mathrm{Ca}^{2+}$ in mononuclear cells (Kimura et al., 2006), which results in a higher susceptibility to peripartal disease. This association has been extensively reported (Curtis et al., 1983; Risco et al., 1984; Chapinal et al., 2011) and may be related to the lack of adequate ionized Ca concentrations required for smooth muscle contractions (Hansen et al., 2003), together with limited supply of glucose and ionized $\mathrm{Ca}$ for adequate immune function. Oral calcium supplementation has been proposed as a complement to dietary means of managing hypocalcemia in dairy herds (Oetzel, 2013) and could be targeted to cows at the highest risk to develop disease.

We hypothesized that the concentration of serum calcium at peripartum and at PM diagnosis will be lower in cows affected by PM compared with matched control cows. Consequently, the addition of oral calcium to the PM treatment would improve cow recovery and subsequent health and fertility. Therefore, the objective of the study was to evaluate the effect of oral calcium administration on the cure, survival, subsequent presentation of peripartal health disorders [clinical and subclinical mastitis, pneumonia, and purulent vaginal discharge (PVD)], and reproductive performance of Holstein cows diagnosed with PM under certified organic management. A second objective was to evaluate the metabolic status (calcium and fatty acid serum concentrations) at calving and at the time of diagnosis in PM and matched healthy control cows.

\section{MATERIALS AND METHODS}

The West Texas A\&M University Institutional Animal Care \& Use Committee approved the animalrelated procedures in this study.

\section{Study Population}

The study population consisted of Holstein cows from a single large certified organic dairy farm $(7,150$ milking cows) located in the Texas panhandle. All cows were housed in freestall barns with sand-bedded stalls and free access to a contiguous dry lot. Prepartum primiparous and multiparous cows were comingled. Cows were milked thrice daily and milk yield was recorded monthly for individual cows. The rolling herd average milk production was $8,600 \mathrm{~kg}$. Cows were fed a TMR twice a day to meet or exceed the nutritional requirements for a lactating Holstein cow producing $30 \mathrm{~kg} / \mathrm{d}$ of milk with $3.5 \%$ fat and $3.1 \%$ true protein (NRC, 2001). During the grazing season (May to September), cows had access to pasture and grazing provided a significant portion of the total ration. Through the study period prepartum diet was based on corn silage (10.5 to $16.0 \%$, DM basis), wheat silage (10.5 to $16.6 \%$ ), alfalfa hay (32 to $41 \%$ ), grass hay (14.2 to $20 \%$ ), grain mix (12.6 to $19.2 \%)$, and mineral and vitamin mix $(3.8 \%)$. Anionic salts were included into the ration (dietary cation anion difference $=-100 \mathrm{mEq} / \mathrm{kg}$ ). During the nongrazing season, the postpartum diet consisted of corn silage (14 to $17.5 \%$ ); wheat silage (13 to $20 \%$ ); a premix containing soybean, soy hulls, corn, wheat, and minerals and vitamins ( 47.5 to $50.5 \%$ ); sorghum silage (3.0 to $4.5 \%$ ); alfalfa hay (12 to $16 \%$ ); and grass hay (0 to $3 \%$ ). 
During the grazing season, postpartum diet consisted of corn silage ( 5 to $7 \%$ ); wheat silage (17 to $19 \%$ ); a premix containing soybean, soy hulls, corn, wheat, and minerals and vitamins (38 to $41 \%$ ); sorghum silage (5 to $7 \%$ ); alfalfa hay ( $2 \%)$; grass hay (0 to $1.5 \%$ ); and pasture grazing (estimated as 30 to $38 \%$ ).

\section{Postpartum Health-Monitoring Program}

Fresh cows were monitored daily between 0600 and $0800 \mathrm{~h}$, following the AM milking, for general health from calving to 12 DIM. Main parameters considered were appetite, appearance (depressed, dehydrated, and so on), and characteristics of vaginal discharge (color, consistency, and odor). Cows that appeared abnormal on any of these parameters were submitted for clinical examination by a veterinarian. At examination, all animals were evaluated for body condition using a 5 -point $(1=$ emaciated to $5=$ obese) system (Ferguson et al., 1994) and had their vaginal discharge inspected using the Metricheck device (Metricheck, SimcroTech, Hamilton, New Zealand). Vaginal discharge was scored (VDS) according to Chenault et al. (2004) as follows: $0=$ no discharge observed; $1=$ not fetid, normal lochia (viscous; red, brown, or clear); $2=$ not fetid; thick mucus; cloudy, clearing, or clear; $3=$ not fetid; may be purulent, mucopurulent, or chocolate brown; or 4 = fetid; may be red or pink to chocolate brown; thin, serous, and watery; with or without pieces of necrotic tissue. Per rectum palpation was conducted to establish a uterine score (UTS, modified from Zemjanis, 1970). Uterine score considered the size and tonicity of the uterus at the greater curvature of the uterine horn (1 $=$ flaccid uterus larger than one hand, $2=$ uterus with moderate to high tonicity and smaller than one hand). Rectal temperature (RT) was measured in submitted cows using an electronic thermometer (GLA Agricultural Electronics, San Luis Obispo, CA).

At d 32 after calving, lactating cows were screened for presence of PVD by one of the authors. Vaginal discharge was scored using a 5-point scale (LeBlanc et al., 2002): 1 = clear mucus or translucent mucus; $2=$ cloudy mucus with flecks of pus; $3=$ mucopurulent (approximately 50\% mucus and 50\% pus present); 4 $=$ purulent $(>50 \%$ pus present); $5=$ watery, reddish $/$ brownish color and foul smell. Cows with VDS $\geq 3$ at examination were defined as positive for PVD. The time of PM diagnosis was considered study d 0 and corresponded with the start of treatment.

\section{Reproductive Management}

Cows enrolled in the study were subject to a reproductive program based on AI using visual estrus detec- tion. Cows' tailheads were painted daily with colored chalk and checked for signs of estrus by removal of tail chalk. If estrus was determined, cows were artificially inseminated during the morning. None of the cows were subjected to any type of estrus or ovulation synchronization protocol. All the farm personnel performing estrus detection and artificial insemination were blinded to PM and treatment status of the study cows. The reported voluntary waiting period was $45 \mathrm{~d}$, and pregnancy diagnosis was performed by transrectal palpation at $60 \mathrm{~d}$ after AI.

\section{Case Definition and Treatment Allocation}

All dairy cows calving between June 2014 and August 2015 and experiencing PM between d 1 and 12 after calving were eligible for enrollment. Cows with PM were defined as having an abnormally enlarged uterus with VDS of 4, signs of systemic illness (decreased milk yield, dullness, or other signs of toxemia) and fever $\left(\mathrm{RT} \geq 39.5^{\circ} \mathrm{C}\right.$ ) within 12 DIM (Sheldon et al., 2006). Lactating cows that were concurrently affected by any health disorders other than uterine conditions at the time of enrollment were excluded from the study. In addition, cows that had a cesarean section, fetotomy, or uterine prolapse were also excluded from the analyses. Consequently, the following criteria were required for lactating cows to be enrolled in the present study: $\leq 12$ DIM, RT $\geq 39.5^{\circ} \mathrm{C}$, VDS of 4 , signs of systemic illness, and absence of exclusion criteria described above. Cows diagnosed with PM $(\mathrm{n}=200)$ were blocked by parity and randomly assigned into 1 of 2 treatment groups. All cows received the same IU treatment and were randomly assigned to also receive oral calcium supplementation or not. The IU treatment was based on a previous study that reported an effective treatment protocol suitable for organic dairies (Pinedo et al., 2015). Treatments were applied every other day for a total of 3 consecutive treatments as follows: (1) control $(\mathbf{C O N})$ received $3.75 \mathrm{~mL}$ of Optimum UterFlush [Van Beek Natural Science, Orange City, IA, containing yucca extract, cinnamaldehyde, thymol, and a proprietary blend of carvacrol (4-isopropyl-2-methylphenol, at $0.47 \mathrm{~g} / \mathrm{mL})$ ] diluted in $117 \mathrm{~mL}$ of distilled water intrauterus ( $\mathrm{n}=100) ;(2)$ calcium supplemented (CA) received the same intrauterine treatment plus 6 calcium oral capsules ('O' Cal-D Cap, Bio-Vet Inc., Barneveld, WI; 7,500-9,000 mg of Ca/capsule) once per day, for 3 consecutive days. According to the study farm health protocols, all treated cows received hypertonic saline solution $(500 \mathrm{~mL}$ of $7.2 \%$ i.v.), dextrose $(500 \mathrm{~mL}$ of $50 \%$ i.v.), and oral aspirin [ 5 boluses (15.6 g of acetylsalicylic acid/bolus)/d for $3 \mathrm{~d}$ ]. Calcium oral capsules contained 7,500 to $9,000 \mathrm{mg}$ of calcium and 5,000 IU of vitamin 
$\mathrm{D}_{3}$. The resulting total dose per treatment/cow was 45 to $54 \mathrm{~g}$ of calcium. Ingredients included calcium propionate, calcium carbonate, calcium chloride, calcium acetate, and calcium lactate. The dose of calcium was similar to that reported by Oetzel (2013).

\section{Monitoring, Events of Interest, and Independent Variables}

At the time of PM diagnosis, each enrolled cow was matched with a non-PM healthy control $(\mathbf{C H})$ cow in the same parity and within \pm 3 DIM relative to the affected cow and a blood sample was collected. All cows that calved during the study period had blood samples collected approximately 12 to $24 \mathrm{~h}$ after calving for fatty acid and calcium determination, as this is the period when cows typically experience low blood Ca concentrations (Kimura et al., 2006; Sampson et al., 2009). Serum was harvested and stored frozen for subsequent analyses in PM and matched $\mathrm{CH}$ cows. Blood samples were also collected in PM cows at $\mathrm{d} 1,2,3$, and 6 after diagnosis. Total serum calcium concentrations were determined at these 5 time points. For PM and matched $\mathrm{CH}$ cows, fatty acid serum concentration were measured at enrollment whereas BHB concentrations were determined at enrollment and at the d 6 examination. Subclinical hypocalcemia was considered when serum calcium concentration $<2.15 \mathrm{mmol} / \mathrm{L}$ (Martinez et al., 2012). Lactating cows were considered to have elevated fatty acids if serum fatty acid concentration $>0.7 \mathrm{mmol} / \mathrm{L}$ (Ospina et al., 2010). Subclinical ketosis was defined as serum BHB $\geq 1.2 \mathrm{mmol} / \mathrm{L}$ (Ospina et al., 2010).

Enrolled cows fitting our inclusion criteria for PM had their RT assessed AM (0600 to 0800 h) daily from $\mathrm{d} 0$ to 6 . A complete clinical examination by a veterinarian was performed at d 6 and 14. Outcome variables for treatment efficacy included fever (RT $\geq$ $39.5^{\circ} \mathrm{C}$ ), presence of fetid vaginal discharge (VDS = $4)$, and uterine size and tonicity (UTS $=1$ ) at study d 6 and 14. Clinical cure was defined as the combination of absence of fever and VDS $<4$ (Chenault et al., 2004). Survival (at 6, 14, 30, and 100 DIM), and reproductive performance (percentage of cows AI at 150 DIM, DIM to first AI, pregnancy at first AI, and percentage of pregnant cows at 200 DIM) were also assessed. Veterinarians responsible for clinical examinations were blinded to allocation groups and the nature of treatments. Peripartal health disorders were defined as follows: clinical mastitis $=$ visible abnormalities in the milk; udder quarter may be hot, swollen, hard, or painful with watery or serous secretion; and subclinical mastitis = linear SCS $\geq 4.5$; pneumonia $=$ acute presentation of elevated RT $\left(\geq 40^{\circ} \mathrm{C}\right)$, accompanied by cough and high respiratory rates. Nasal discharge and increased bronchial sounds at lung auscultation may occur. Control variables included parity $(1$ or $\geq 2)$, BCS at enrollment ( $0 ; \leq 2.5$ or $>2.5$ ), access to pasture, and calving season.

\section{Statistical Analyses}

The experimental design was a randomized block design with PM cows blocked by parity and assigned randomly into 1 of 2 treatment groups. Sample size calculations were performed using the PROC POWER procedure of SAS (release 9.2, SAS Institute Inc., Cary, $\mathrm{NC}$ ). The sample size was calculated to detect a difference of 20 percentage points in the main outcome variable, clinical cure (absence of fever at d 14 and VDS < 4) in favor of the treatment group (CA). Based on a previous report, a cure rate for cows in the CON group of $50 \%$ was anticipated (Pinedo et al., 2015). Considering power $=80 \%$ and confidence $=95 \%$, the number of cows required to show a significant difference between the 2 treatment groups was estimated in 93 cows per group.

Logistic regression (PROC GLIMMIX, SAS) was used for the analysis of binary outcome variables, whereas continuous variables were evaluated by ANOVA (PROC GLM, SAS). The appropriate randomization of cows at the time of enrollment for discrete outcomes was analyzed by the chi-squared test (PROC FREQ). Analyses of appropriate randomization for continue variables were performed by the use of the Tukey test (LSMEANS statement). Univariate analyses were used to test the inclusion of each explanatory variable in the final models. Effects with a $P$-value $<0.20$ were included in the initial multivariable analysis, and the final models were tested through a backward elimination procedure. The significance level for inclusion in the final model was set at $P<0.10$ to account for potential confounders affecting both the response and the predictors. Treatment was forced into the final models, and interactions between the effect of treatment and significant covariates were considered.

Time-to-event analyses were performed for reproductive outcomes. Hazard distributions for time to first AI and pregnancy were calculated using the actuarial method of the LIFETEST procedure of SAS to test the null hypothesis that the survivor functions (time from calving to a reproductive event) were identical for the 2 groups receiving a different treatment. Additionally, a Cox proportional regression model was developed to 
evaluate the effect of multiple variables on the risk of $\mathrm{AI}$ and pregnancy (PROC PHREG). Statistical significance was set at $P<0.05$.

\section{RESULTS}

\section{Descriptive Statistics}

Overall, 200 lactating Holstein cows (106 primiparous and 94 multiparous) diagnosed with $\mathrm{PM}$ were enrolled in the study $(\mathrm{CA}=100 ; \mathrm{CON}=100)$ and matched with $200 \mathrm{CH}$ cows at the time of diagnosis. Mean ( \pm SEM) parity was $1.92(0.12), 2.08$ (0.14), and 2.14 (0.10) for CON, CA, and $\mathrm{CH}$ groups, respectively. The DIM at enrollment were $6.2(0.16), 6.0$ (0.17), and 6.1 (0.12) for $\mathrm{CON}, \mathrm{CA}$, and $\mathrm{CH}$ groups, respectively. Mean ( \pm SEM) BCS at enrollment were 2.78 (0.02) for CON and 2.81 (0.02) for CA. None of these variables were significantly different between groups.

\section{Metabolic Status and PM}

Serum fatty acid concentrations at calving (0.48 vs. $0.37 \mathrm{mmol} / \mathrm{L}, P<0.0001)$ and at the day of diagnosis were higher in $\mathrm{PM}$ cows than in $\mathrm{CH}$ cows (0.49 vs. $0.35 \mathrm{mmol} / \mathrm{L}$, respectively; $P<0.0001)$. Prevalence of serum fatty acid concentration $>0.7 \mathrm{mmol} / \mathrm{L}$ at calving were 13.2 versus $7.7 \%$ for $\mathrm{PM}$ and $\mathrm{CH}$ groups, respectively. The odds $(95 \% \mathrm{CI}$ ) of fatty acids $>0.7 \mathrm{mmol} / \mathrm{L}$ at calving were $3.12(1.94-5.02)$ times higher for PM compared with $\mathrm{CH}$ cows. Concentrations of fatty acids at calving were similar for normocalcemic and hypocalcemic cows $(0.41$ and $0.42 \mathrm{mmol} / \mathrm{L}$, respectively). At the day of PM diagnosis, prevalence of fatty acids $>0.7 \mathrm{mmol} / \mathrm{L}$ was 19.5 and $11.7 \%$ for the $\mathrm{PM}$ and $\mathrm{CH}$ groups, respectively $(P=0.03)$.

No differences were observed in average serum concentrations of BHB between PM $(0.52 \mathrm{mmol} / \mathrm{L})$ and $\mathrm{CH}(0.49 \mathrm{mmol} / \mathrm{L})$ at the time of diagnosis. Prevalence of subclinical ketosis (serum BHB $\geq 1.2 \mathrm{mmol} / \mathrm{L}$ ) at $\mathrm{d}$ 0 was 7.0 and $4.6 \%$ for the PM and $\mathrm{CH}$ groups, respectively $(P=0.3)$.

No differences were found for calcium concentrations at calving between groups ( 2.11 vs. $2.06 \mathrm{mmol} / \mathrm{L}$ for $\mathrm{PM}$ and $\mathrm{CH}$, respectively). Prevalence of serum $\mathrm{Ca}$ concentration $<2.15 \mathrm{mmol} / \mathrm{L}$ at calving was 42 and $61 \%$ for PM and $\mathrm{CH}$ groups, respectively $(P=0.001)$. At diagnosis, serum calcium concentrations were lower in $\mathrm{PM}$ cows $(1.57 \mathrm{mmol} / \mathrm{L})$ compared with $\mathrm{CH}$ cows $(2.10 \mathrm{mmol} / \mathrm{L} ; P<0.001)$ and prevalence of serum Ca $<2.15 \mathrm{mmol} / \mathrm{L}$ was 90 and $49 \%$ for PM and $\mathrm{CH}$ groups, respectively $(P<0.001)$. No significant differences between $\mathrm{CON}$ and $\mathrm{CA}$ groups at calving and at the day of diagnosis were identified for any of these conditions.
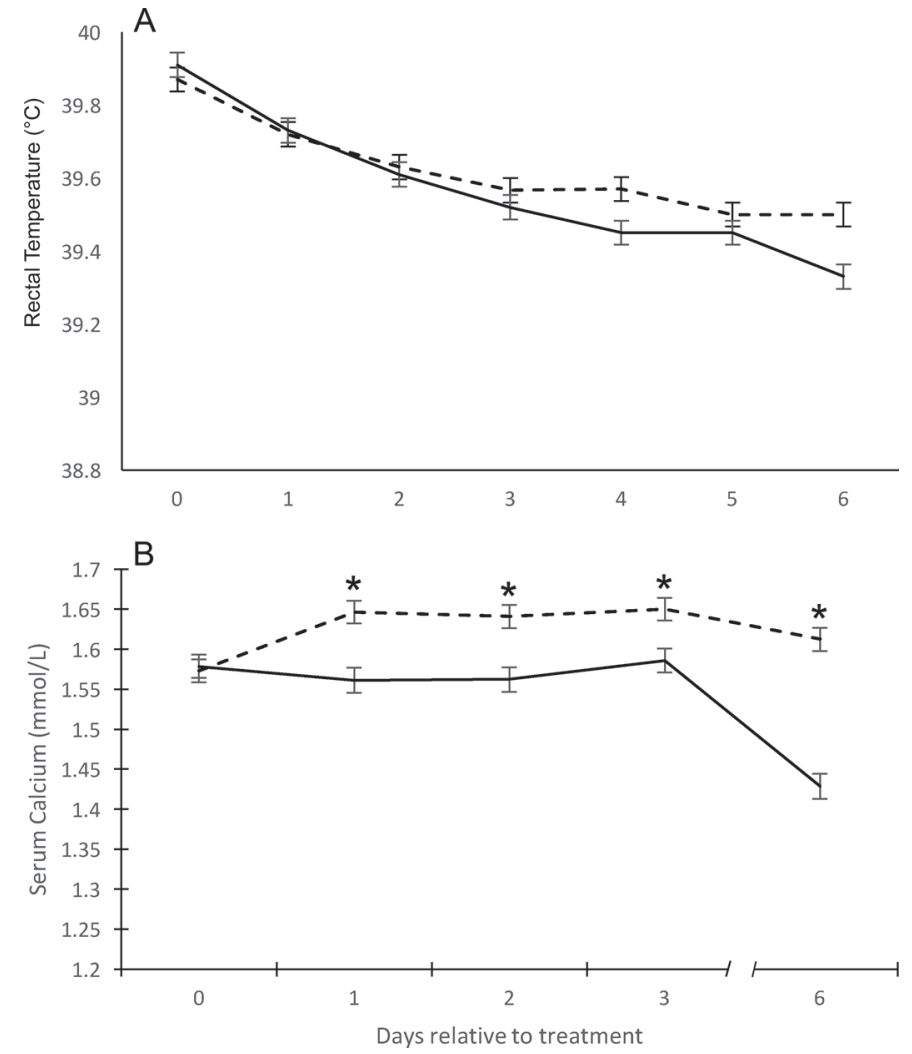

Figure 1. Rectal temperatures (A) and serum calcium concentrations (B) by day after treatment initiation. The control group (-) received $3.75 \mathrm{~mL}$ of Optimum UterFlush (Van Beek Natural Science, Orange City, IA) diluted in $117 \mathrm{~mL}$ of distilled water $(\mathrm{n}=100)$; the calcium-supplemented group (- - ) was administered the same intrauterine treatment plus 6 calcium oral capsules ('O' Cal-D Cap, BioVet Inc., Barneveld, WI; 7,500-9,000 mg of Ca/capsule) once per day, for $3 \mathrm{~d}$. Average calcium concentration in the healthy control group at d 0 was $2.10 \mathrm{mmol} / \mathrm{L}$. Error bars represent SE. *Indicates significant differences at $P<0.05$.

As expected, serum concentrations of calcium at d 1 , 2,3 , and 6 post-PM diagnosis were significantly higher in the CA treatment group compared with the CON group $(P=0.0004$, Figure 1$)$. No differences in serum concentrations of BHB were determined at $\mathrm{d} 6$ between $\mathrm{PM}(0.41 \mathrm{mmol} / \mathrm{L})$ and $\mathrm{CH}(0.36 \mathrm{mmol} / \mathrm{L}, P=0.2)$.

\section{Culling, Rectal Temperature, Vaginal Discharge Score, and Uterine Score}

A total of 185 and 165 cows with PM were evaluated on study d 6 and 14, respectively. A total of 7 (4 were culled and 3 died) and 8 cows (6 were culled and 2 died) from $\mathrm{CON}$ and CA groups were not present at the farm at d 6 after enrollment. Additionally, a total of 19 (13 were culled and 6 died) and 16 cows (13 were culled and 3 died) from $\mathrm{CON}$ and $\mathrm{CA}$ groups were not present for examination at $14 \mathrm{~d}$ postdiagnosis. In the $\mathrm{CH}$ group, 1 cow died and 2 cows were culled before d 14 . 
The main reasons for culling lactating cows within 14 DIM were low milk production and low BCS $(\mathrm{CON}=$ 10 and $\mathrm{CA}=10)$, a worsened metritis condition $(\mathrm{CON}$ $=2$ and $\mathrm{CA}=2)$, and pneumonia $(\mathrm{CON}=1$ and $\mathrm{CA}$ $=1$ ). The findings from necropsy of dead cows were hemorrhagic bowel syndrome $(\mathrm{CON}=2$ and $\mathrm{CA}=$ $1)$, peritonitis $(\mathrm{CON}=2)$, pneumonia $(\mathrm{CON}=1$ and $\mathrm{CA}=1)$, and worsened metritis condition $(\mathrm{CA}=1)$. No significant findings were found in one $\mathrm{CON}$ cow at necropsy.

No significant effect was found for calcium treatment on fever (Figure 1), presence of fetid vaginal discharge, UTS, or clinical cure at study d 6 and 14 (Tables 1 and 2).

\section{Subsequent Health Disorders and Survival}

Purulent vaginal discharge at 32 DIM was not affected by treatment. Treatment group was not associated with incidence of subsequent health disorders.

Survival at 30 DIM was 84,79 , and $98.5 \%$ for CA, $\mathrm{CON}$, and $\mathrm{CH}$ cows, respectively, whereas survival at 100 DIM was higher $(P<0.001)$ for $\mathrm{CH}$, followed by $\mathrm{CA}$ and CON cows $(96,80$, and $74 \%$ respectively); survival was not different between CA and CON (Table 3).

\section{Reproductive Performance}

Overall, 55 and $66 \%$ of the cows in $\mathrm{CON}$ and $\mathrm{CA}$ groups received the first AI by 150 DIM, respectively. The median $(95 \% \mathrm{CI})$ for the number of days to first AI was $81 \mathrm{~d}(69-91 \mathrm{~d})$ and $78 \mathrm{~d}(72-86 \mathrm{~d})$ for CON and CA groups, respectively $(P=0.7)$. Conversely, $91 \%$ of the cows in the $\mathrm{CH}$ group were inseminated by 150 DIM, and the median $(95 \% \mathrm{CI})$ for days from calving to first AI was $62 \mathrm{~d}(60-66 \mathrm{~d})$. These 2 values were different from the CON and CA groups $(P<0.001$ and $P<$ 0.002 , respectively).

The probability of being inseminated by 150 DIM was associated with treatment, parity, $\mathrm{SCH}$ at calving, and DIM at the time of PM diagnosis (Table 4). According to the survival analyses (Figure 2), no differences were observed regarding risk for first AI between $\mathrm{CA}$ and CON groups $(P=0.11)$, but the mean for days from calving to first AI was smaller for $\mathrm{CH}$ cows $(P<0.001)$. When the overall enrolled population of study cows was considered, the percentage of cows both inseminated and pregnant at first AI was 18.5, 22.8, and $43 \%$ for CON, CA, and CH groups, respectively $(P<0.001)$. Pregnancy at first postpartum AI was 35.4 and $36.2 \%$ for CON and CA groups, respectively $(P=0.46)$, whereas $50.1 \%$ of $\mathrm{CH}$ cows were diagnosed pregnant to first AI $(P<0.001)$.
Overall, $74 \%$ of $\mathrm{CH}$ cows were pregnant by 200 DIM, whereas $37 \%$ of CON cows and $39 \%$ of CA cows were pregnant by 200 DIM. The difference between CON and CA groups was not significant $(P=0.90)$, but $\mathrm{CH}$ cows differed from the PM cows $(P<0.001)$.

The odds of pregnancy by 200 DIM were associated with parity and DIM at PM diagnosis (Table 4). Median $(95 \% \mathrm{CI})$ for the number of days to pregnancy was $93 \mathrm{~d}(83-125 \mathrm{~d})$ and $91 \mathrm{~d}(75-109 \mathrm{~d})$ for CON and CA groups, respectively $(P=0.7)$. The median $(95 \% \mathrm{CI})$ for days from calving to pregnancy for the $\mathrm{CH}$ group was $75 \mathrm{~d}(68-84 \mathrm{~d})$ and differed from the PM cows $(P$ $<0.001)$.

Table 1. Distribution of study cows by outcome categories of clinical variables examined at d 6 and 14 after puerperal metritis diagnosis ${ }^{1}$

\begin{tabular}{|c|c|c|c|}
\hline \multirow[b]{2}{*}{ Variable } & \multicolumn{2}{|c|}{ Treatment } & \multirow[b]{2}{*}{$P$-value ${ }^{2}$} \\
\hline & $\begin{array}{c}\text { CON, no. } \\
(\%)\end{array}$ & $\begin{array}{c}\text { CA, no. } \\
(\%)\end{array}$ & \\
\hline \multicolumn{4}{|l|}{ Clinical exam at d 6} \\
\hline Present at exam & $92(92)$ & $93(93)$ & 0.98 \\
\hline \multirow{2}{*}{\multicolumn{4}{|c|}{$\operatorname{VDS}^{3}(\Omega 1=09.5 \mathrm{C})$}} \\
\hline & & & \\
\hline 1 & $8(8.6)$ & $7(7.6)$ & 0.97 \\
\hline 2 & $23(24.7)$ & $22(23.9)$ & \\
\hline 3 & $41(44.1)$ & $40(43.5)$ & \\
\hline 4 & $21(22.6)$ & $23(25)$ & \\
\hline \multicolumn{4}{|l|}{$\stackrel{4}{\mathrm{UTS}^{4}}$} \\
\hline 1 & $47(50.5)$ & $47(51.1)$ & 0.94 \\
\hline 2 & $46(49.5)$ & $45(48.9)$ & \\
\hline Clinical cure ${ }^{5}$ & $55(59)$ & $49(53)$ & 0.69 \\
\hline \multicolumn{4}{|l|}{ Clinical exam at d 14} \\
\hline Present at exam & $81(81.0)$ & $84(84.0)$ & 0.97 \\
\hline Fever $\left(\mathrm{RT} \geq 39.5^{\circ} \mathrm{C}\right)$ & $10(12.8)$ & $10(11.8)$ & 0.83 \\
\hline \multicolumn{4}{|l|}{ VDS } \\
\hline 1 & $17(20.9)$ & $17(21.1)$ & 0.71 \\
\hline 2 & $30(37.6)$ & $32(38.4)$ & \\
\hline 3 & $31(38.8)$ & $29(34.9)$ & \\
\hline 4 & $2(1.9)$ & $5(5.8)$ & \\
\hline \multicolumn{4}{|l|}{ UTS } \\
\hline 1 & $19(23.3)$ & $15(17.5)$ & 0.36 \\
\hline 2 & $62(76.7)$ & $69(82.5)$ & \\
\hline Clinical cure & $72(78.2)$ & $73(78.5)$ & 0.78 \\
\hline
\end{tabular}

${ }^{1} \mathrm{~A}$ total of 200 affected cows from one organic farm received intrauterine therapy and were randomly assigned to additionally receive oral calcium supplementation or not. Treatments were applied every other day for a total of 3 times: CON received $3.75 \mathrm{~mL}$ of Optimum UterFlush (Van Beek Natural Science, Orange City, IA) diluted in 117 $\mathrm{mL}$ of distilled water intrauterus $(\mathrm{n}=100)$; $\mathrm{CA}$ received the same intrauterine treatment plus 6 calcium oral capsules ('O' Cal-D Cap, Bio-Vet Inc., Barneveld, WI; 7,500-9,000 mg of Ca/capsule) once per day, for 3 consecutive days.

${ }^{2}$ As indicated by chi-squared test.

${ }^{3}$ Vaginal discharge score (VDS): $0=$ no discharge observed; $1=$ not fetid, normal lochia; 2 = not fetid; thick mucus; cloudy, clearing, or clear; 3 = not fetid; may be purulent, mucopurulent, or chocolate brown; or $4=$ fetid.

${ }^{4}$ Uterine score (UTS): 1 = flaccid uterus larger than one hand, $2=$ uterus with moderate to high tonicity and smaller than one hand. ${ }^{5}$ Clinical cure: rectal temperature $(\mathrm{RT})<39.5^{\circ} \mathrm{C}$ and $\operatorname{VDS}<4$. 
Table 2. Results from the multivariable logistic regression analyses by outcome categories of clinical variables examined at d 6 and 14 after puerperal metritis diagnosis for 200 cows that received intrauterine therapy and were randomly assigned to additionally receive oral calcium supplementation or not $^{1}$

\begin{tabular}{|c|c|c|c|}
\hline Variable & $\mathrm{OR}^{2}$ & $95 \% \mathrm{CI}$ & $P$-value \\
\hline \multicolumn{4}{|l|}{ d 6} \\
\hline \multirow{2}{*}{\multicolumn{4}{|c|}{ Fever $\left(\mathrm{RT} \geq 39.5^{\circ} \mathrm{C}\right)$}} \\
\hline \multicolumn{3}{|l|}{ Treatment } & \\
\hline $\mathrm{CA}$ & 1.41 & $0.74-2.65$ & 0.29 \\
\hline $\mathrm{CON}$ & Referent & - & - \\
\hline DIM at diagnosis ${ }^{3}$ & 0.75 & $0.61-0.92$ & 0.005 \\
\hline \multicolumn{4}{|l|}{$\operatorname{VDS}=4^{4}$} \\
\hline \multicolumn{4}{|l|}{ Treatment } \\
\hline $\mathrm{CA}$ & 1.01 & $0.50-2.05$ & 0.97 \\
\hline $\mathrm{CON}$ & Referent & - & - \\
\hline DIM at diagnosis & 0.67 & $0.532-0.859$ & 0.001 \\
\hline Mean (d) & Referent & - & - \\
\hline \multicolumn{4}{|l|}{$\mathrm{UTS}=1^{5}$} \\
\hline \multicolumn{4}{|l|}{ Treatment } \\
\hline $\mathrm{CA}$ & 0.95 & $0.53-1.73$ & 0.88 \\
\hline $\mathrm{CON}$ & Referent & - & - \\
\hline \multicolumn{4}{|l|}{ d 14} \\
\hline \multicolumn{4}{|l|}{ Fever $\left(\mathrm{RT} \geq 39.5^{\circ} \mathrm{C}\right)$} \\
\hline \multicolumn{4}{|l|}{ Treatment } \\
\hline CA & 0.82 & $0.33-2.09$ & 0.71 \\
\hline $\mathrm{CON}$ & Referent & - & - \\
\hline \multicolumn{4}{|l|}{$\mathrm{VDS}=4$} \\
\hline \multicolumn{4}{|l|}{ Treatment } \\
\hline $\mathrm{CA}$ & 0.4 & $0.075-2.12$ & 0.28 \\
\hline $\mathrm{CON}$ & Referent & - & - \\
\hline \multicolumn{4}{|l|}{$\mathrm{UTS}=1$} \\
\hline \multicolumn{4}{|l|}{ Treatment } \\
\hline $\mathrm{CA}$ & 0.66 & $0.30-1.46$ & 0.31 \\
\hline $\mathrm{CON}$ & Referent & - & - \\
\hline
\end{tabular}

${ }^{1}$ Only treatment group (forced in the final models) and variables with $P$-value $<0.10$ are presented. Treatments were applied every other day for a total of 3 times: CON received $3.75 \mathrm{~mL}$ of Optimum UterFlush (Van Beek Natural Science, Orange City, IA) diluted in $117 \mathrm{~mL}$ of distilled water intrauterus $(\mathrm{n}=100)$; CA received the same intrauterine treatment plus 6 calcium oral capsules ('O' Cal-D Cap, Bio-Vet Inc., Barneveld, WI; 7,500-9,000 $\mathrm{mg}$ of $\mathrm{Ca} /$ capsule) once per day, for 3 consecutive days. $\mathrm{RT}=$ rectal temperature.

${ }^{2}$ Odds ratio.

${ }^{3}$ Assessed as 1-unit offsets (increase) from the mean.

${ }^{4}$ Vaginal discharge score (VDS): $0=$ no discharge observed; $1=$ not fetid, normal lochia; 2 = not fetid; thick mucus; cloudy, clearing, or clear; 3 = not fetid; may be purulent, mucopurulent, or chocolate brown; or $4=$ fetid

${ }^{5}$ Uterine score (UTS): 1 = flaccid uterus larger than one hand; $2=$ uterus with moderate to high tonicity and smaller than one hand.

\section{DISCUSSION}

The objective was to assess the effect of oral calcium administration as part of the treatment of PM on multiple health and performance outcomes in 200 lactating cows diagnosed with PM on an organic dairy farm.

As a reference for comparison, we matched each PM cow with a healthy cow in the same parity and within \pm 3 DIM relative to the affected cow. Although average DIM for both populations were not different $(6.1 \mathrm{~d})$, this range in days could have an effect on the param-
Table 3. Results from the multivariable logistic regression analyses for survival at 30 and 100 DIM in 200 cows with puerperal metritis that received intrauterine therapy and were randomly assigned to additionally receive oral calcium supplementation or not ${ }^{1}$

\begin{tabular}{|c|c|c|c|}
\hline Variable & $\mathrm{OR}^{2}$ & $95 \% \mathrm{CI}$ & $P$-value \\
\hline \multicolumn{4}{|l|}{$30 \mathrm{DIM}$} \\
\hline \multirow{2}{*}{\multicolumn{4}{|c|}{$\begin{array}{l}\text { Present at exam } \\
\text { Treatment }^{1}\end{array}$}} \\
\hline & & & \\
\hline CA & 1.56 & $0.72-3.34$ & 0.25 \\
\hline $\mathrm{CON}$ & Referent & - & - \\
\hline \multicolumn{4}{|l|}{ Parity $^{3}$} \\
\hline 1 & 3.75 & $1.63-8.69$ & 0.002 \\
\hline$>1$ & Referent & - & - \\
\hline DIM at diagnosis ${ }^{4}$ & 1.44 & $1.09-1.89$ & 0.008 \\
\hline \multicolumn{4}{|l|}{100 DIM } \\
\hline \multicolumn{4}{|l|}{ Present at exam } \\
\hline \multicolumn{4}{|l|}{ Treatment } \\
\hline $\mathrm{CA}$ & 1.57 & $0.80-3.20$ & 0.20 \\
\hline $\mathrm{CON}$ & Referent & - & - \\
\hline \multicolumn{4}{|l|}{ Parity } \\
\hline 1 & 3.23 & $1.54-6.80$ & 0.002 \\
\hline$>1$ & Referent & - & - \\
\hline DIM at diagnosis & 1.39 & $1.09-1.78$ & 0.007 \\
\hline
\end{tabular}

${ }^{1}$ Only treatment group (forced in the final models) and variables with $P$-value $<0.10$ are presented. Treatments were applied every other day for a total of 3 times: CON received $3.75 \mathrm{~mL}$ of Optimum UterFlush (Van Beek Natural Science, Orange City, IA) diluted in $117 \mathrm{~mL}$ of distilled water intrauterus $(n=100)$; CA received the same intrauterine treatment plus 6 calcium oral capsules ('O' Cal-D Cap, Bio-Vet Inc. Barneveld, WI; 7,500-9,000 mg of $\mathrm{Ca} /$ capsule) once per day, for 3 consecutive days.

${ }^{2}$ Odds ratio.

${ }^{3}$ Parity $1 ; \geq 2$.

${ }^{4}$ Assessed as 1-unit offsets (increase) from the mean.

eters under analysis, as they are highly variable during the first week after calving.

Although our results supported an association between calcium and PM, as indicated by lower serum concentrations in affected cows compared with $\mathrm{CH}$ at the time of diagnosis, the effects of calcium supplementation as provided in the treatment were negligible. Although cows in the CA group showed a significant increase in serum calcium during therapy, this increment resulted in concentrations below those of the $\mathrm{CH}$ group and was not associated with the anticipated improvement in cure. Rectal temperature decreased gradually from d 0 to 14 and the repeated measures analysis indicated no difference between treatment groups. This reduction in fever after treatment initiation is consistent with previous reports, and in this study it is probably associated with the administration of aspirin (Benzaquen et al., 2007; McLaughlin et al., 2012; Pinedo et al., 2015). Interestingly, a decline in $\mathrm{RT}$ in metritic cows that remained untreated has been reported, indicating spontaneous cure (Chenault et al., 2004; McLaughlin et al., 2012; Sannmann et al., 2013).

Clinical cure for VDS $(<4)$ at d 6 and 14 was similar in both treatment groups. More than $94 \%$ of the cows 
PINEDO ET AL.

Table 4. Results from the multivariable logistic regression analyses for reproductive outcomes ${ }^{1}$

\begin{tabular}{|c|c|c|c|}
\hline Variable & $\mathrm{OR}^{2}$ & $95 \% \mathrm{CI}$ & $P$-value \\
\hline \multicolumn{4}{|l|}{$\mathrm{AI}<150 \mathrm{DIM}$} \\
\hline \multicolumn{4}{|l|}{ Treatment $^{1}$} \\
\hline $\mathrm{CA}$ & 1.89 & $1.01-3.61$ & 0.05 \\
\hline $\mathrm{CON}$ & Referent & - & - \\
\hline \multicolumn{4}{|l|}{ Parity $^{3}$} \\
\hline 1 & 2.43 & $1.26-4.68$ & 0.009 \\
\hline$>1$ & Referent & - & - \\
\hline \multicolumn{4}{|c|}{ Subclinical hypocalcemia at calving } \\
\hline No & 2.20 & $1.02-4.75$ & 0.04 \\
\hline Yes & Referent & - & - \\
\hline DIM at diagnosis ${ }^{4}$ & 0.45 & $0.21-0.97$ & 0.002 \\
\hline \multicolumn{4}{|l|}{ Pregnancy at first AI } \\
\hline \multicolumn{4}{|l|}{ Treatment } \\
\hline CA & 0.85 & $0.41-1.77$ & 0.66 \\
\hline $\mathrm{CON}$ & Referent & - & - \\
\hline \multicolumn{4}{|c|}{ Pregnancy at 200 DIM } \\
\hline \multicolumn{4}{|l|}{ Treatment } \\
\hline $\mathrm{CA}$ & 1.11 & $0.59-2.09$ & 0.73 \\
\hline $\mathrm{CON}$ & Referent & - & - \\
\hline \multicolumn{4}{|l|}{ Parity } \\
\hline 1 & 2.87 & $1.51-5.43$ & 0.001 \\
\hline$>1$ & Referent & - & - \\
\hline DIM at diagnosis & 1.30 & $1.08-1.58$ & 0.005 \\
\hline
\end{tabular}

${ }^{1}$ A total of 200 affected cows from 1 organic farm received intrauterine therapy and were randomly assigned to additionally receive oral calcium supplementation or not. Only treatment group (forced in the final models) and variables with $P$-value $<0.10$ are presented. Treatments were applied every other day for a total of 3 times: CON received $3.75 \mathrm{~mL}$ of Optimum UterFlush (Van Beek Natural Science, Orange City, IA) diluted in $117 \mathrm{~mL}$ of distilled water intrauterus $(\mathrm{n}=100)$; CA received the same intrauterine treatment plus 6 calcium oral capsules ('O' Cal-D Cap, Bio-Vet Inc., Barneveld, WI; 7,500-9,000 mg of Ca/capsule) once per day, for 3 consecutive days.

${ }^{2}$ Odds ratio.

${ }^{3}$ Parity $1 ; \geq 2$

${ }^{4}$ Assessed as 1-unit offsets (increase) from the mean.

in both groups had VDS $<4$ by study d 14 , which is in agreement with a previous study in which more than $90 \%$ of the cows treated with povidone-iodine or UterFlush intrauterine had VDS $<4$ by study d 14 (Pinedo et al., 2015). A recent study using a similar criterion for evaluation of VDS reported that more than $80 \%$ of cows with metritis treated with systemic antibiotic cleared fetid discharge by d 12 after diagnosis (Lima et al., 2014).

Our assessment of horn size and tonicity to determine the level of uterine involution is subjective and represents a limitation of this study. The process of involution begins immediately after calving and involves uterine contractions, physical shrinking, necrosis, sloughing of caruncular material, and regeneration of the endometrium (Sheldon and Dobson, 2004). Variation in uterine tonicity and size might be a reflection of uterine contractility, resulting in a reduction of uterine diameter (Slama et al., 1991). As adequate ionized Ca concentrations required for smooth muscle contractions (Hansen et al., 2003), we anticipated an effect of calcium administration on uterine involution. However,
UTS based on uterus size and tonicity were similar for both groups at d 6 and 14 .

As expected, survival at $30 \mathrm{~d}$ was lower in PM compared with $\mathrm{CH}$ cows (81 vs. $98.5 \%$, respectively) whereas survival at $100 \mathrm{~d}$ was 77 and $96.0 \%$ for PM and $\mathrm{CH}$ groups, respectively. However, neither of the survival categories was different between CA and CON groups.

Cows in the $\mathrm{CH}$ group had a significantly better reproductive performance when compared with both groups of PM cows, confirming the need for adequate prevention and treatment of uterine diseases. A similar detrimental effect of PM on reproductive performance was previously reported (Pinedo et al., 2015). That study reported that $75 \%$ of cows in the healthy control group were pregnant by 150 DIM, whereas $37 \%$ of cows previously affected by PM were pregnant by 150 DIM. In a study by Giuliodori et al. (2013), cows with PM, compared with healthy controls, had lower risk for pregnancy by 100 DIM, a lower hazard rate for pregnancy by 150 DIM, and took longer to get pregnant. Studies analyzing antibiotic therapy reported smaller 
subsequent effects of PM on reproduction compared with our results. A recent study (Lima et al., 2013) analyzing the efficacy for antibiotic treatment of metritis reported pregnancy per AI values for cows with PM were higher than those resulting from our study (26.4\%). Furthermore, Benzaquen et al. (2007) reported no difference in the first-service pregnancy risk and the pregnancy risk at 150 DIM between normal cows and cows with PM that were treated with antibiotics; similarly, no difference was found for calving-to-first AI interval and calving-to pregnancy intervals. However, in these studies cows were subject to synchronization of ovulation protocols that included hormonal treatments, particularly $\mathrm{PGF}_{2 \alpha}$, which could benefit uterine health, although pregnancy per AI was not significantly affected (Dubuc et al., 2011; Lima et al., 2013). Unfortunately, due to well-being considerations, a nontreated control group was not included in our study, and therefore, we were not able to determine the magnitude of the effect of the 2 treatments on clinical outcomes and subsequent reproductive performance.

When comparing the 2 groups of affected cows, the only reproductive outcome affected by calcium treatment in our study was the proportion of cows inseminated by 150 DIM with a larger proportion in the CA group (66 vs. $55 \%$ for $\mathrm{CA}$ and $\mathrm{CON}$ groups, respectively; $P=0.05)$. The association between calcium concentration and reproductive performance has been previously reported. Martinez et al. (2012) reported that cows with SCH had a longer interval to pregnancy compared with normocalcemic cows. Chapinal et al. (2012) concluded that low concentrations of calcium around parturition were associated with lower probability of pregnancy at first AI.

Interestingly, contrary to what was expected, although average calcium concentrations at calving in PM and $\mathrm{CH}$ cows were not different, prevalence of serum $\mathrm{Ca}$ concentration $<2.15 \mathrm{mmol} / \mathrm{L}$ at calving was higher in the CH group (61 vs. $42 \%$ ). This situation was reverted at PM diagnosis, where 90 and $49 \%$ of $\mathrm{PM}$ and $\mathrm{CH}$ cows had Ca concentration $<2.15 \mathrm{mmol} / \mathrm{L}$. In addition, at that time Ca was lower in PM cows $(1.57 \mathrm{mmol} / \mathrm{L})$ compared with $\mathrm{CH}$ cows $(2.10 \mathrm{mmol} / \mathrm{L})$. Although this finding may suggest that, as presented by Martinez et al. (2012), low calcium concentrations could predispose to PM, it is also plausible that reduced feed intake before clinical signs would affect serum calcium levels.

Notably, other studies have also failed in demonstrating the association between low calcium concentrations and worsened health; Chamberlin et al. (2013) reported that hypocalcemic $([\mathrm{iCa}]<1.0 \mathrm{mmol} / \mathrm{L})$ and normocalcemic cows at calving had similar incidence of health disorders, including metritis, and no differences were stablished in the proportions cycling at 50

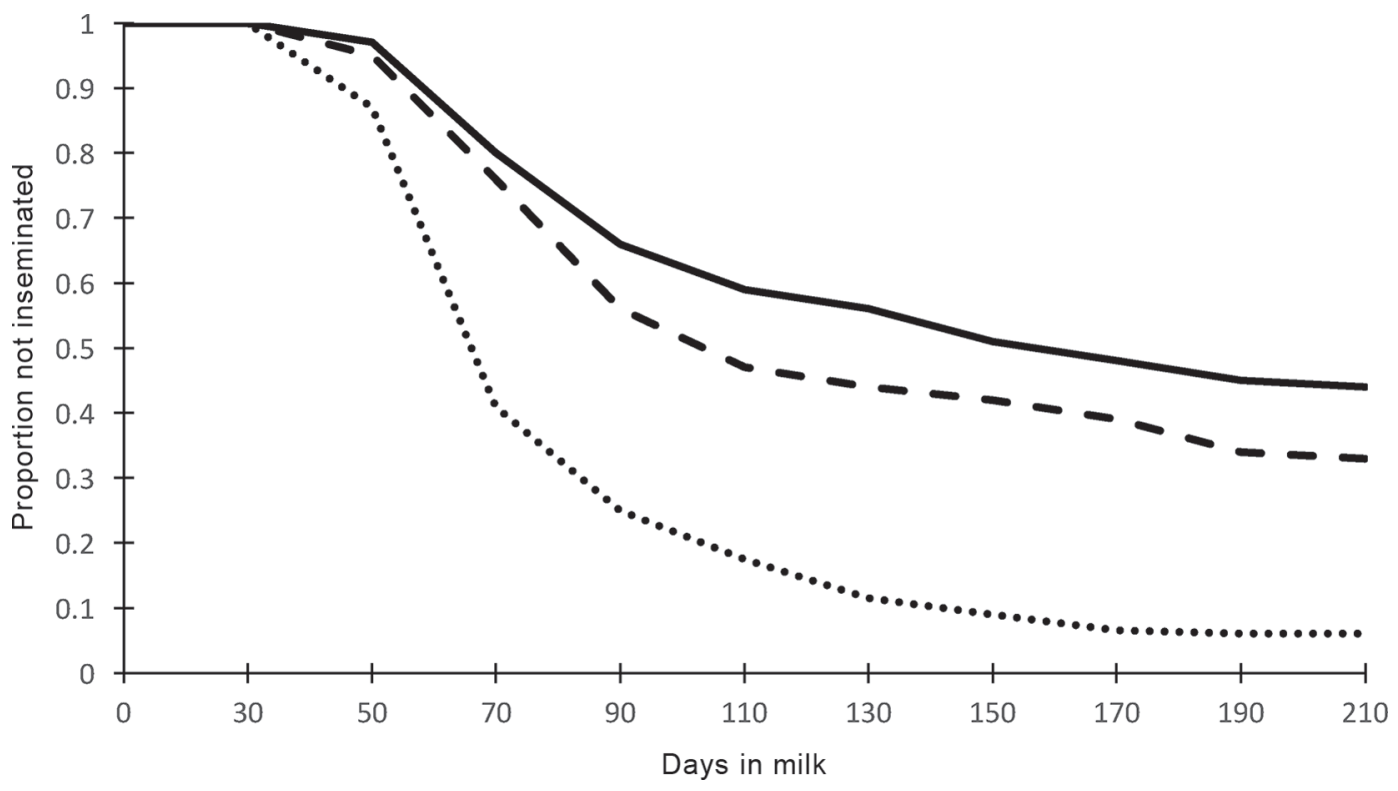

Figure 2. Survival curves for the interval from calving to first AI by treatment group. Median (95\% CI) days from calving to first AI were control $=81 \mathrm{~d}(69-91 \mathrm{~d})$ and calcium-supplemented $=78 \mathrm{~d}(72-86 \mathrm{~d} ; P=0.7)$. The adjusted hazard ratio $=1.34$ (calcium-supplemented vs. control treatment; $P=0.11$ ). The control group $(-)$ received $3.75 \mathrm{~mL}$ of Optimum UterFlush (Van Beek Natural Science, Orange City, IA) diluted in $117 \mathrm{~mL}$ of distilled water intrauterus $(\mathrm{n}=100)$; the calcium-supplemented group $(---)$ received the same intrauterine treatment plus 6 calcium oral capsules ('O' Cal-D Cap, Bio-Vet Inc., Barneveld, WI; 7,500-9,000 mg of Ca/capsule) once per day, for 3 consecutive days. The healthy control group $(\cdots)$, consisting of cows calving during the same period of time without any postpartum disorder, is included as a reference for comparison. Median (95\% CI) for days from calving to first AI in the healthy control group was $62 \mathrm{~d}(60-66 \mathrm{~d} ; P<0.001)$. 
to 60 DIM, or time to pregnancy between hypocalcemic and normocalcemic cows. At calving, serum fatty acid concentrations were higher in PM compared with $\mathrm{CH}$ cows. Nonetheless, this difference persisted until the time of PM diagnosis, supporting the role of NEB as a risk factor for this uterine disease.

\section{CONCLUSIONS}

Supplementing oral calcium at the time of organic PM treatment had no effect on clinical cure or survival. High fatty acid concentration at calving was a significant risk factor for occurrence of PM. Cows experiencing PM had lower calcium and higher fatty acid concentrations at the time of diagnosis.

\section{ACKNOWLEDGMENTS}

The authors thank Bio-Vet Inc. (Barneveld, WI), which supplied calcium oral capsules ('O' Cal-D Cap) for this study.

\section{REFERENCES}

Benzaquen, M. E., C. A. Risco, L. F. Archbald, P. Melendez, M. J. Thatcher, and W. W. Thatcher. 2007. Rectal temperature, calving-related factors, and the incidence of puerperal metritis in postpartum dairy cows. J. Dairy Sci. 90:2804-2814.

Burton, J. L., S. A. Madsen, L. C. Chang, P. S. Weber, K. R. Buckham, R. van Dorp, M. C. Hickey, and B. Earley. 2005. Gene expression signatures in neutrophils exposed to glucocorticoids: A new paradigm to help explain "neutrophil dysfunction" in parturient dairy cows. Vet. Immunol. Immunopathol. 105:197-219.

Chamberlin, W. G., J. R. Middleton, J. N. Spain, G. C. Johnson, M. R. Ellersieck, and P. Pithua. 2013. Subclinical hypocalcemia, plasma biochemical parameters, lipid metabolism, postpartum disease, and fertility in postparturient dairy cows. J. Dairy Sci. 96:7001-7013.

Chapinal, N., M. Carson, T. F. Duffield, M. Capel, S. Godden, M. Overton, J. E. P. Santos, and S. J. LeBlanc. 2011. The association of serum metabolites with clinical disease during the transition period. J. Dairy Sci. 94:4897-4903.

Chapinal, N., M. E. Carson, S. J. LeBlanc, K. E. Leslie, S. Godden, M. Capel, J. E. P. Santos, M. W. Overton, and T. F. Duffield. 2012 The association of serum metabolites in the transition period with milk production and early-lactation reproductive performance. J. Dairy Sci. 95:1301-1309.

Chenault, J. R., J. F. McAllister, S. T. Chester, K. J. Dame, F. M. Kausche, and E. J. Robb. 2004. Efficacy of ceftiofur hydrochloride sterile suspension administered parenterally for the treatment of acute postpartum metritis in dairy cows. JAVMA 224:1634-1639.

Curtis, C. R., H. N. Erb, and C. J. Sniffen. 1983. Association of parturient hypocalcemia with eight periparturient disorders in Holstein cows. J. Am. Vet. Med. Assoc. 183:559-561.

DeGaris, P. J., and I. J. Lean. 2008. Milk fever in dairy cows: A review of pathophysiology and control principles. Vet. J. 176:58-69.

Dubuc, J., T. F. Duffield, K. E. Leslie, J. S. Walton, and S. J. LeBlanc. 2011. Randomized clinical trial of antibiotic and prostaglandin treatments for uterine health and reproductive performance in dairy cows. J. Dairy Sci. 94:1325-1338.

Ducusin, R. J., Y. Uzuka, E. Satoh, M. Otani, M. Nishimura, S. Tanabe, and T. Sarashina. 2003. Effects of extracellular $\mathrm{Ca}^{2+}$ on phagocytosis and intracellular $\mathrm{Ca}^{2+}$ concentrations in polymor- phonuclear leukocytes of postpartum dairy cows. Res. Vet. Sci. $75: 27-32$.

Ferguson, J. D., D. T. Galligan, and N. Thomsen. 1994. Principal descriptors of body condition score in Holstein cows. J. Dairy Sci. $77: 2695-2703$

Gilbert, R. O., S. T. Shin, C. L. Guard, H. N. Erb, and M. Frajblat. 2005. Prevalence of endometritis and its effects on reproductive performance of dairy cows. Theriogenology 64:1879-1888.

Giuliodori, M. J., R. P. Magnasco, D. Becu-Villalobos, I. M. LacauMengido, C. A. Risco, and R. L. de la Sota. 2013. Metritis in dairy cows: Risk factors and reproductive performance. J. Dairy Sci. 96:3621-3631.

Goff, J. P. 2004. Macromineral disorders of the transition cow. Vet. Clin. North Am. Food Anim. Pract. 20:471-494.

Grummer, R. R., D. G. Mashek, and A. Hayirli. 2004. Dry matter intake and energy balance in the transition period. Vet. Clin. North Am. Food Anim. Pract. 20:447-470.

Hammon, D. S., I. M. Evjen, T. R. Dhiman, J. P. Goff, and J. L. Walters. 2006. Neutrophil function and energy status in Holstein cows with uterine health disorders. Vet. Immunol. Immunopathol. 113:21-29

Hansen, S. S., P. Norgaard, C. Pedersen, R. J. Jorgensen, L. S. Mellau, and J. D. Enemark. 2003. The effect of subclinical hypocalcemia induced by $\mathrm{Na}_{2}$ EDTA on the feed intake and chewing activity of dairy cows. Vet. Res. Commun. 27:193-205.

Horst, R. L., J. P. Goff, and T. A. Reinhardt. 2005. Adapting to the transition between gestation and lactation: Differences between rat, human and dairy cow. J. Mammary Gland Biol. Neoplasia 10:141-156.

Horst, R. L., and N. A. Jorgensen. 1982. Elevated plasma cortisol during induced and spontaneous hypocalcemia in ruminants. J. Dairy Sci. 65:2332-2337.

Kimura, K., T. A. Reinhardt, and J. P. Goff. 2006. Parturition and hypocalcemia blunts calcium signals in immune cells of dairy cattle. J. Dairy Sci. 89:2588-2595.

LeBlanc, S. J. 2008. Postpartum uterine disease and dairy herd reproductive performance: A review. Vet. J. 176:102-114.

LeBlanc, S. J., T. F. Duffield, K. E. Leslie, K. G. Bateman, G. P. Keefe, J. S. Walton, and W. H. Johnson. 2002. Defining and diagnosing postpartum clinical endometritis and its impact on reproductive performance in dairy cows. J. Dairy Sci. 85:2223-2236.

Lima, F. S., R. S. Bisinotto, E. S. Ribeiro, L. F. Greco, H. Ayres, M. G. Favoreto, M. R. Carvalho, K. N. Galvao, and J. E. P. Santos. 2013. Effects of one or two treatments with prostaglandin $\mathrm{F}_{2 \alpha}$ on subclinical endometritis and fertility in lactating dairy cows inseminated by timed AI. J. Dairy Sci. 96:6480-6488.

Lima, F. S., A. Vieira-Neto, G. S. F. M. Vasconcellos, R. D. Mingoti, E. Karakaya, E. Solé, R. S. Bisinotto, N. Martinez, C. A. Risco, K. N. Galvão, and J. E. P. Santos. 2014. Efficacy of ampicillin trihydrate or ceftiofur hydrochloride for treatment of metritis and subsequent fertility in dairy cows. J. Dairy Sci. 97:5401-5414.

Martinez, N., C. A. Risco, F. S. Lima, R. S. Bisinotto, L. F. Greco, E. S. Ribeiro, F. Maunsell, K. Galvão, and J. E. Santos. 2012. Evaluation of peripartal calcium status, energetic profile, and neutrophil function in dairy cows at low or high risk of developing uterine disease. J. Dairy Sci. 95:7158-7172.

Martinez, N., L. D. Sinedino, R. S. Bisinotto, E. S. Ribeiro, G. C. Gomes, F. S. Lima, L. F. Greco, C. A. Risco, K. N. Galvão, D. Taylor-Rodriguez, J. P. Driver, W. W. Thatcher, and J. E. Santos. 2014. Effect of induced subclinical hypocalcemia on physiological responses and neutrophil function in dairy cows. J. Dairy Sci. 97:874-887.

McLaughlin, C. L., E. Stanisiewski, M. J. Lucas, C. P. Cornell, J. Watkins, L. Bryson, J. K. S. Tena, J. Hallberg, and J. R. Chenault. 2012. Evaluation of two doses of ceftiofur crystalline free acid sterile suspension for treatment of metritis in lactation dairy cows. J. Dairy Sci. 95:4363-4371.

NAHMS (National Animal Health and Monitoring System). 2002 Dairy 2002 Part I: Reference of Dairy Health and Management in the United States. Natl. Anim. Health Monit. Syst., US Dept. Ag- 
ric., Anim. Plant Health Insp. Serv., Vet. Serv., Cent. Epidemiol. Anim. Health, Fort Collins, CO.

National Research Council. 2001. Nutrient Requirements of Dairy Cattle. 7th rev. ed. Natl. Acad. Sci., Washington, DC.

Oetzel, G. R. 2013. Oral calcium supplementation in peripartum dairy cows. Vet. Clin. North Am. Food Anim. Pract. 29:447-455.

Ospina, P. A., D. V. Nydam, T. Stokol, and T. R. Overton. 2010. Association between the proportion of sampled transition cows with increased nonesterified fatty acids and beta-hydroxybutyrate and disease incidence, pregnancy rate, and milk production at the herd level. J. Dairy Sci. 93:3595-3601.

Pinedo, P. J., J. S. Velez, H. Bothe, D. Merchan, J. M. Piñeiro, and C. A. Risco. 2015. Effect of intrauterine infusion of an organic certified product on uterine health, survival, and fertility of dairy cows with toxic puerperal metritis. J. Dairy Sci. 98:3120-3132.

Reinhardt, T. A., J. D. Lippolis, B. J. Mc Cluskey, J. P. Goff, and R. L. Horst. 2011. Prevalence of subclinical hypocalcemia in dairy herds. Vet. J. 188:122-124.

Risco, C. A., J. P. Reynolds, and D. Hird. 1984. Uterine prolapse and hypocalcemia in dairy cows. J. Am. Vet. Med. Assoc. 185:15171519.

Sampson, J. D., J. N. Spain, C. Jones, and L. Carstensen. 2009. Effects of calcium chloride and calcium sulfate in an oral bolus given as a supplement to postpartum dairy cows. Vet. Ther. 10:131-139.
Sannmann, I., O. Burfeind, R. Voigtsberger, and W. Heuwieser. 2013. Comparison of two monitoring and treatment strategies for cows with acute puerperal metritis. Theriogenology 79:961-969.

Santos, J. E. P. R. S. Bisinotto, E. S. Ribeiro, F. S. Lima, L. F. Greco, C. R. Staples, and W. W. Thatcher. 2010. Applying nutrition and physiology to improve reproduction in dairy cattle. Soc. Reprod. Fertil. Suppl. 67:387-403.

Sheldon, I. M., and H. Dobson. 2004. Postpartum uterine health in cattle. Anim. Reprod. Sci. 82-83:295-306.

Sheldon, I. M., G. S. Lewis, S. LeBlanc, and R. O. Gilbert. 2006. Defining postpartum uterine disease in cattle. Theriogenology 65:1516-1530.

Slama, H., D. Vaillancourt, and A. K. Goff. 1991. Pathophysiology of the puerperal period: Relationship between prostaglandin E2 (PGE2) and uterine involution in the cow. Theriogenology 36:1071-1090.

Stojkov, J., M. A. G. von Keyserlingk, J. N. Marchant-Forde, and D. M. Weary. 2015. Assessment of visceral pain associated with metritis in dairy cows. J. Dairy Sci. 98:5352-5361.

Zemjanis, R. 1970. Examination of the cow. Pages 3-87 in Diagnostic and therapeutic techniques in animal reproduction. 2nd ed. R. Zemjanis, ed. The Williams \& Wilkins Company, Waverly Press Inc., Baltimore, MD 